Research Article

\title{
Effect of Sizing Agents on Surface Properties of T800 Grade CF and Thermal Aging Time on Mechanical Properties of T800 Grade CF/Epoxy Composites
}

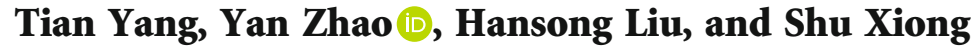 \\ School of Materials Science and Engineering, Beihang University, Beijing 100191, China \\ Correspondence should be addressed to Yan Zhao; jennyzhaoyan@buaa.edu.cn
}

Received 25 May 2021; Revised 24 September 2021; Accepted 6 October 2021; Published 31 October 2021

Academic Editor: Yiqi Yang

Copyright (c) 2021 Tian Yang et al. This is an open access article distributed under the Creative Commons Attribution License, which permits unrestricted use, distribution, and reproduction in any medium, provided the original work is properly cited.

\begin{abstract}
This paper investigates the effect of sizing agent molecular weight on carbon fiber (CF) surface properties and the effect of thermal aging time on mechanical properties of CF/epoxy composites. The surface properties of three CCF800 CF samples with varying sizing agent molecular weight were characterized by surface morphology, surface roughness, chemical functional groups, and element composition. The results showed that the sample with low molecular weight exhibited low roughness and high proportion of activated carbon atoms. The flexural strength, flexural modulus, and interlaminar shear strength of CCF800/5228 composites were measured at $25^{\circ} \mathrm{C}$ and $150^{\circ} \mathrm{C}$ by thermal ageing time $0,100 \mathrm{~h}, 250 \mathrm{~h}, 500 \mathrm{~h}$, and $1000 \mathrm{~h}$. The results showed that the thermal aging time up to $1000 \mathrm{~h}$ had little effect on the flexural modulus, and the interlaminar shear performance at $150^{\circ} \mathrm{C}$ showed a trend of increasing at the beginning and then decreasing.
\end{abstract}

\section{Introduction}

As indispensable reinforcing materials used in advanced composites, carbon fibers (CF) have a series of excellent properties, including high specific strength and modulus, excellent thermal, fatigue, and chemical corrosion resistance [1-3]. CF reinforced composites are suitable for applications such as satellites, launch vehicles, or aircrafts, for reducing weight or improving mechanical performance [4-6]. During their production process, CF must be sized after oxidation treatment, coating a layer of tens to hundreds of nanometers thick organic sizing agents on the surface [7]. Except processability improvement, sizing agents can also effectively increase surface energy and produce active functional groups, which improve wettability and interface bonding performance between CF and matrix [8, 9]. In addition, sizing agents can change surface appearance by generating uneven folds and increasing roughness, which are benefit to interface bonding strength by "anchor effect" [10-12]. In order to acquire one optimized sizing agent for a specific CF reinforced composite, researchers have made many attempts for analyzing different factors of sizing agents, such as chemical composition, molecular weight, dispersion of function groups, solution properties, or molecular modification [13-19]. Among them, molecular weight is considered as an important factor influencing on surface roughness and thermal stability. When applying CF reinforced epoxy matrix composites, actual service life was affected by environment elements, such as temperature, humidity, and ultraviolet light [20]. Thermal aging was pointed out as a main form of composite corrosion failure, which decreased mechanical properties in long time service [21].

As Chinese T800 grade CF are in rapid development, the effect of sizing agents on CCF800 (one of Chinese T800 grade CF) surface properties and the thermal aging properties of CCF800 reinforced composites are worth to be investigated. Three sizing agents varying in molecular 
weight were coated on CCF800 CF during manufacture process. The surface morphology, surface roughness, chemical functional groups, and element composition were measured, and the results were compared and analyzed to describe the effect of sizing agents. The unidirectional and $60 \%$ fiber volume fraction CCF800/5228 composites were made from prepregs. The thermal ageing time was set from 0 to $1000 \mathrm{~h}$. The flexural strength, flexural modulus, and interlaminar shear strength were measured at $25^{\circ} \mathrm{C}$ and $150^{\circ} \mathrm{C}$ in $0,100 \mathrm{~h}, 250 \mathrm{~h}, 500 \mathrm{~h}$, and $1000 \mathrm{~h}$ by ASTM standards. The results exhibited the trends of different mechanical properties during thermal aging.

\section{Experiment}

2.1. Materials. The nominal molecular weight of three sizing agents is shown in Table 1. These sizing agents were sized on CCF800 during manufacture process. Epoxy resin 5228 was obtained from Beijing Institute of Aeronautical Materials. The solvent ethyl alcohol was purchased from Beijing Chemical Works. All reagents were of analytical grade. CCF800/5228 composites were made by prepreg autoclave forming process at $180^{\circ} \mathrm{C}$ for $3 \mathrm{~h}$. CCF800 were unidirectional arranged, and the volume fraction of fiber was $60 \%$.

2.2. Characterization of CCF800. The linear density was tested in accordance with the standard GB/T 3362-2017 Appendix $\mathrm{B}$ and the bulk density in accordance with the standard GB/T 30019-2013 method A.

The surface morphology was acquired using JSM-7500 cold field emission scanning electron microscope (SEM) and Veeco D3000 atomic force microscope (AFM). The scanning area of AFM was selected as $3 \mu \mathrm{m} \times 3 \mu \mathrm{m}$. The software Nano Scope was used to calculate average surface roughness.

The surface chemical functional groups and element composition were analyzed using Thermo Nicolet Nexus 470 Fourier transform infrared spectrometer (FTIR) and ESCALAB250 X-ray photoelectron spectrometer (XPS). The infrared spectrum spectra were obtained from $3500 \mathrm{~cm}^{-1}$ to $500 \mathrm{~cm}^{-1}$. The XPS measurements were carried out by both full-spectrum scanning and high-precision narrow-spectrum scanning. C1s peak was selected to determine the form and proportion of carbon using the XPS Peak software.

2.3. Thermal Stability of Sizing Agents. The sizing agent samples were extracted from CCF800. The thermal stability was performed using the STA449 F3 TG-DSC synchronous thermal analyzer produced by the German NETZSCH company. The weight loss was recorded from room temperature to $500^{\circ} \mathrm{C}$ with a $10^{\circ} \mathrm{C} / \mathrm{min}$ heating rate. Two types of thermogravimetric measurement atmosphere, the nitrogen and air, were selected in this experiment.

2.4. Thermal Aging Properties of CCF800/5228 Composites. The heat treatment condition was set to $(150 \pm 5)^{\circ} \mathrm{C}$ with six groups of ageing time $0,100,250,500,750$, and $1000 \mathrm{~h}$. For each group, flexural strength, flexural modulus, and interlaminar shear strength were tested in both $(25 \pm 3)^{\circ} \mathrm{C}$ and $(150 \pm 5)^{\circ} \mathrm{C}$. Experimental samples, testing machines,
TABLE 1: The nominal sizing agent molecular weight.

\begin{tabular}{lc}
\hline CF & Molecular weight of sizing agent \\
\hline CCF800A & 1520 \\
CCF800B & 4690 \\
CCF800C & 21400 \\
\hline
\end{tabular}

TABLE 2: The linear and bulk density tests of carbon fiber.

\begin{tabular}{lcc}
\hline Carbon fiber & Linear density $(\mathrm{g} / \mathrm{km})$ & Bulk density $\left(\mathrm{g} / \mathrm{cm}^{3}\right)$ \\
\hline CCF800A & $449 \pm 1$ & $1.782 \pm 0.005$ \\
CCF800B & $443 \pm 2$ & $1.788 \pm 0.003$ \\
CCF800C & $448 \pm 1$ & $1.784 \pm 0.005$ \\
\hline
\end{tabular}

and procedures were in accordance with the standard ASTM D7264 for flexural strength and flexural modulus and the standard ASTM D2344 for interlaminar shear strength.

\section{Results and Discussions}

3.1. Linear and Bulk Density. From the results in Table 2, the difference of maximum and minimum bulk density among three CF was $0.006 \mathrm{~g} / \mathrm{cm}^{3}(0.33 \%)$, indicating no significant variation. Bulk density is an inherent property of $\mathrm{CF}$ and often reflects graphite compactness, which is determined by production process. Three CCF800 samples were manufactured in the same process, and this was consistent with the experimental values. Similar situation was also found in the linear density measurements. Linear density of $\mathrm{CF}$ is only affected by fiber diameter and bulk density. Thus, it was concluded that molecular weight of sizing agents did not influence bulk density, linear density, and diameters of CF.

3.2. Surface Morphology and Roughness. The surface and fracture section morphology were observed by SEM as shown in Figure 1. Obvious "grooves" on the surface were found, distributing along the fiber direction. Among three samples, the length, number, and distribution of grooves were almost in the same level, which meant the effect of molecular weight on these factors could not be found by SEM measurement. As a brittle material, the fracture of CF normally generates from crack propagation. Figure 1 exhibits such fracture mode and records the crack sources with different locations. Seen from photos (b) and (d) in Figure 1, the fracture direction was easily found from one specific crack source starting from the surface, while photo (f) exhibited three crack sources of fracture. Therefore, molecular weight of sizing agents might influence the number and location of crack sources.

From AFM three-dimensional images in Figure 2, several grooves were seen clearly along the fiber axis on the surface. In the selected $3 \mu \mathrm{m} \times 3 \mu \mathrm{m}$ area, the height of 


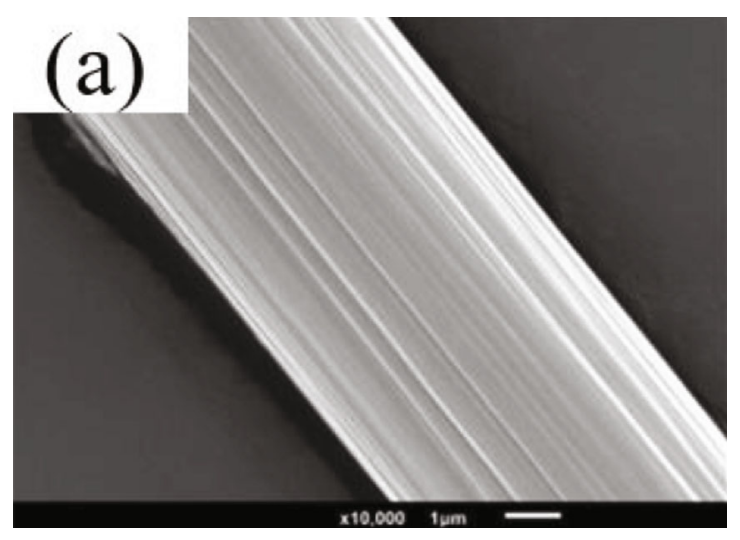

(a)

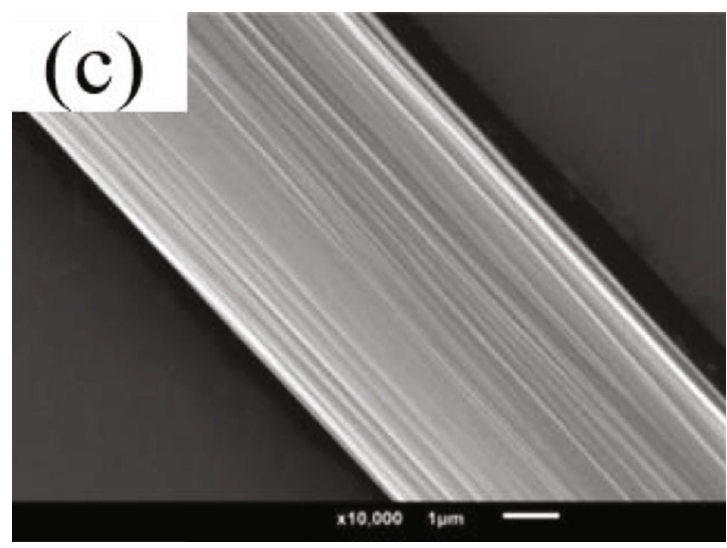

(c)

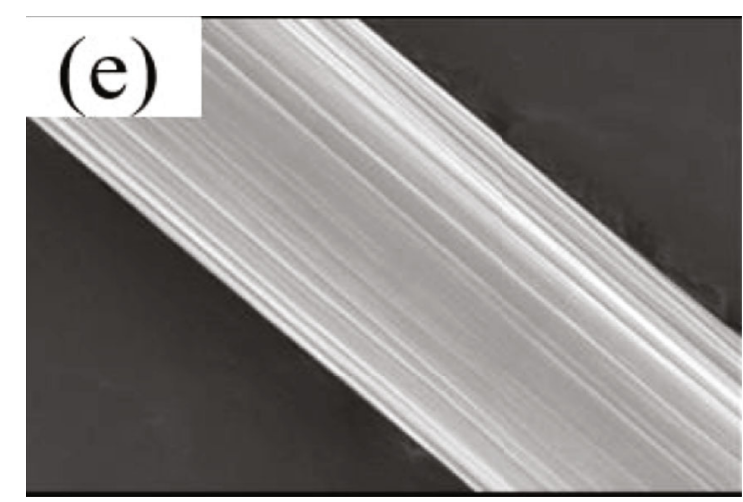

(e)

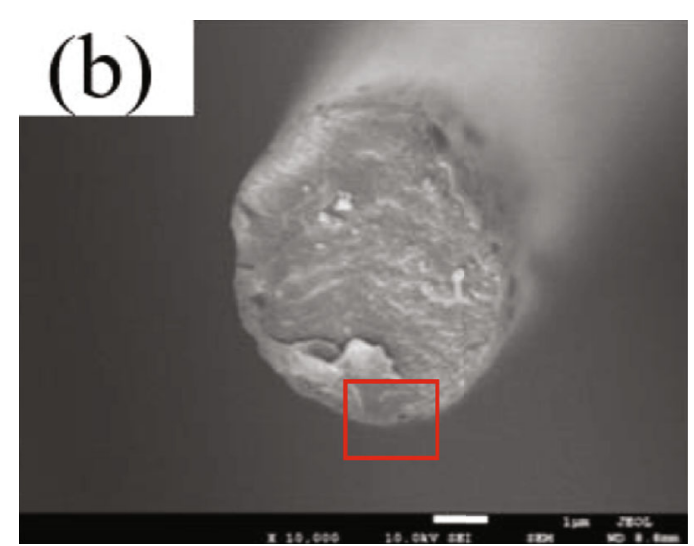

(b)

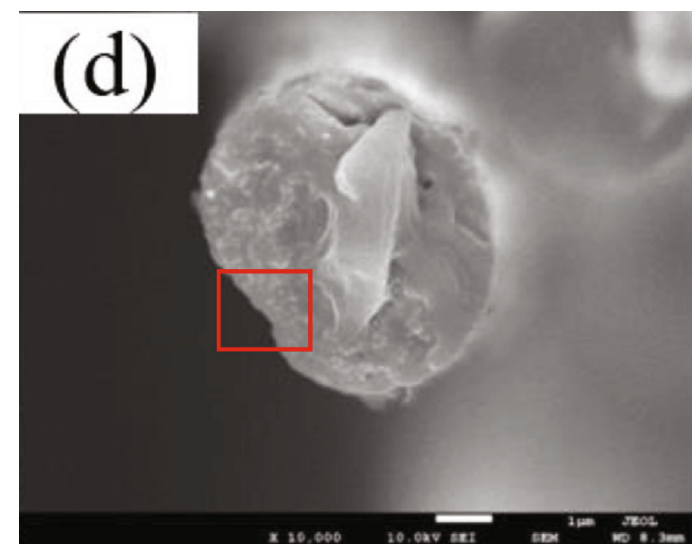

(d)

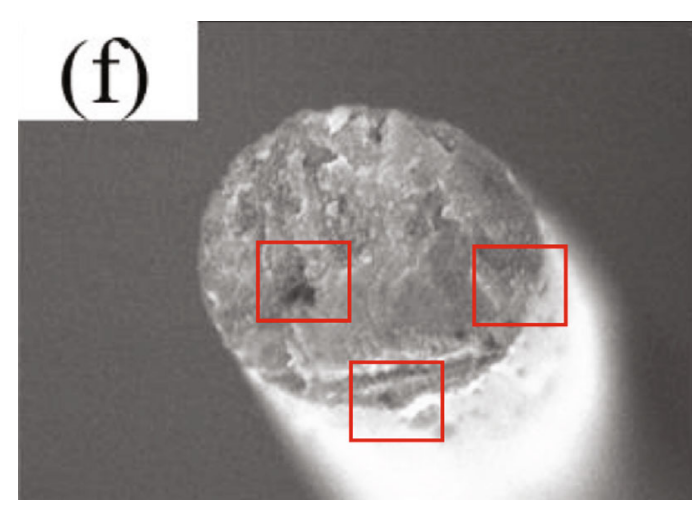

(f)

FIgURE 1: The morphology of surface and fracture section: (a, b) CCF800A; (c, d) CCF800B; (e, f) CCF800C.

CCF800A surface was the smallest among these three CF, which reflected the lowest surface roughness in Table 3. The surface roughness of CCF800B and CCF800C were quite similar, $32.63 \mathrm{~nm}$ and $32.60 \mathrm{~nm}$, respectively, and that of CCF $800 \mathrm{~A}$ was $25 \%$ less. It proved that molecular weight of sizing agents had an effect on surface roughness, and CF with small molecular weight of sizing agents exhibited low surface roughness.

3.3. Surface Chemical Functional Groups and Element Composition. Seven signification peaks appeared in Figure 3,
$2960 \mathrm{~cm}^{-1}$ (asymmetric stretching vibration $-\mathrm{CH}_{3}$ ), $1727 \mathrm{~cm}^{-1}$ (-CHO flexural vibration peak), $1506 \mathrm{~cm}^{-1}$ (benzene ring vibration peak), $1250 \mathrm{~cm}^{-1}$ (typical epoxide C-O peak), $1044 \mathrm{~cm}^{-1}$ (-CO- flexural vibration peak), $916 \mathrm{~cm}^{-1}$ (terminal epoxy ring peak), and $830 \mathrm{~cm}^{-1}$ (para-substituted benzene ring out-of-plane deformation and cis-epoxide C-O peak). According to the typical epoxide $\mathrm{C}-\mathrm{O}$, cis-epoxide $\mathrm{C}-\mathrm{O}$, or terminal epoxy ring peak, it was speculated that bisphenol A epoxy resin was main component of these sizing agents. Thus, these sizing agents were suitable for epoxy resin in manufacturing composites. 
(a1)

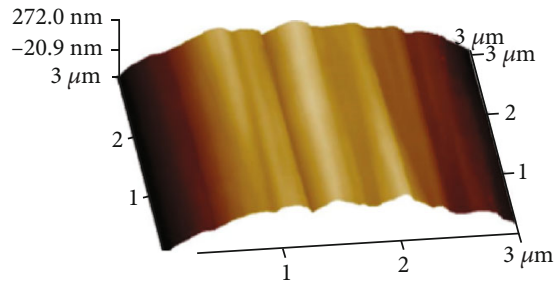

(a2)

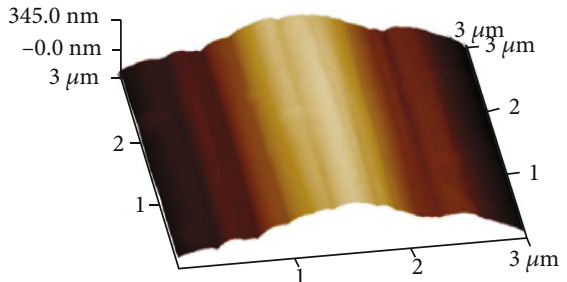

(a3)

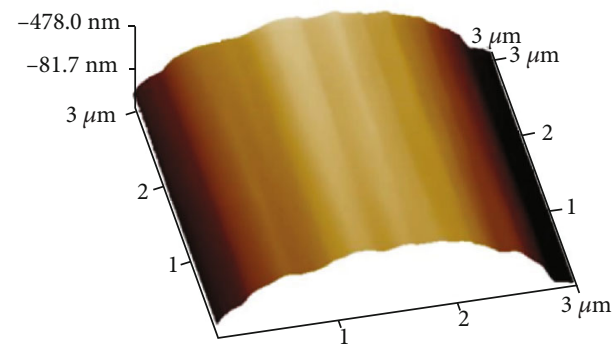

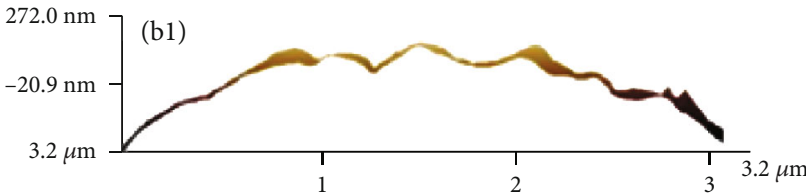
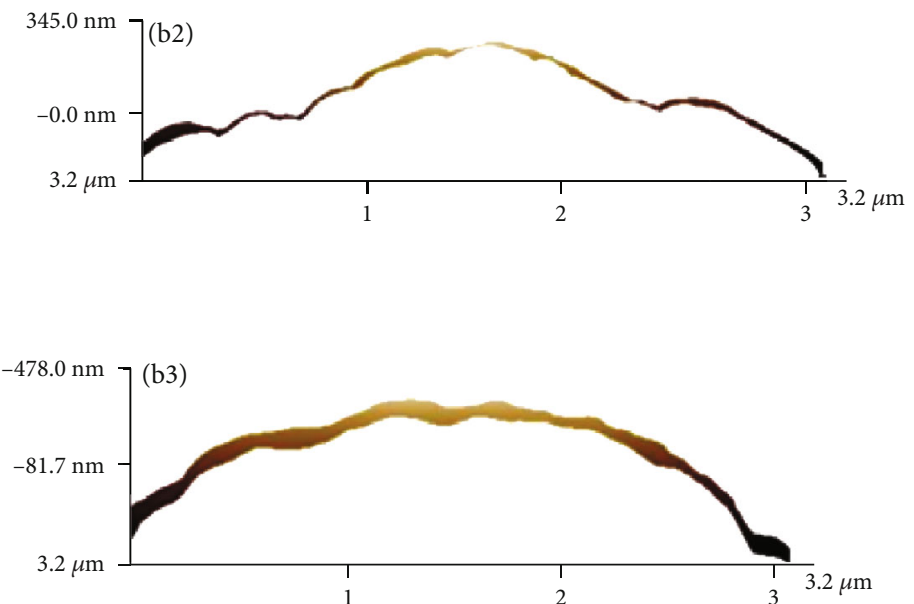

Figure 2: The surface AFM topography of carbon fibers: (a) CCF800A; (b) CCF800B; (c) CCF800C.

TABLE 3: The surface roughness of carbon fiber.

\begin{tabular}{lc}
\hline Carbon fiber & Roughness $(\mathrm{Ra} / \mathrm{nm})$ \\
\hline CCF800A & $24.58 \pm 1.01$ \\
CCF800B & $32.63 \pm 3.56$ \\
CCF800C & $32.60 \pm 2.32$ \\
\hline
\end{tabular}

As detection depth of full-spectrum scanning XPS was no more than $10 \mathrm{~nm}$ and thickness of sizing agents coated on the surface was normally tens to hundreds of nanometers [7], XPS analysis of CF was regarded as elemental analysis of sizing agents. From the results in Figure 4, there were two strong peaks, $287 \mathrm{eV}$ for $\mathrm{C} 1$ s peak and $531 \mathrm{eV}$ for O1s peak. With outstanding elements $\mathrm{C}$ and $\mathrm{O}$, the conjecture that sizing agents used bisphenol A epoxy resin as the main component was further proved.

In order to find out the form and proportion of element $\mathrm{C}$, the narrow XPS scanning of the C1s fitting peak was obtained by the XPS Peak software as shown in Figure 5. The fitting results are listed in Table 4 . The meaningful point was that the activated carbon atom ratio of CCF800A (32.66\%) was much higher that CCF800B (27.34\%) and CCF800C (28.54\%). Thus, CF with low molecular weight of sizing agents exhibited high activated carbon atom proportion.

3.4. Thermal Stability of Sizing Agents. TG curves are shown in Figure 6, and the temperatures of $5 \%$ and $10 \%$ weight loss

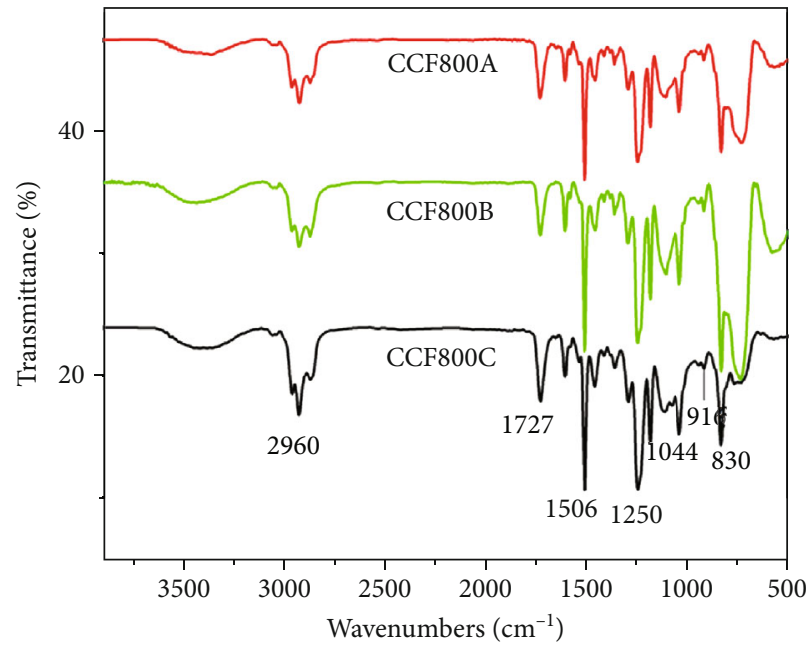

Figure 3: The Fourier transform infrared spectra of CF.

for each sample are listed in Table 5. It was seen that the temperatures of $5 \%$ weight loss of these three agents were above $270^{\circ} \mathrm{C}$ in both $\mathrm{N}_{2}$ and air. Both the temperatures of $5 \%$ or $10 \%$ of CCF $800 \mathrm{C}$ were a little higher than those of CCF800A and CCF800B, which meant high molecular weight improved the thermal stability, but the improvement was limited and not meaningful.

When temperature reached over $300^{\circ} \mathrm{C}$, the lost in weight became more severe. As thermal decomposition temperature of epoxy resin is normally $300^{\circ} \mathrm{C}$, these curves in 


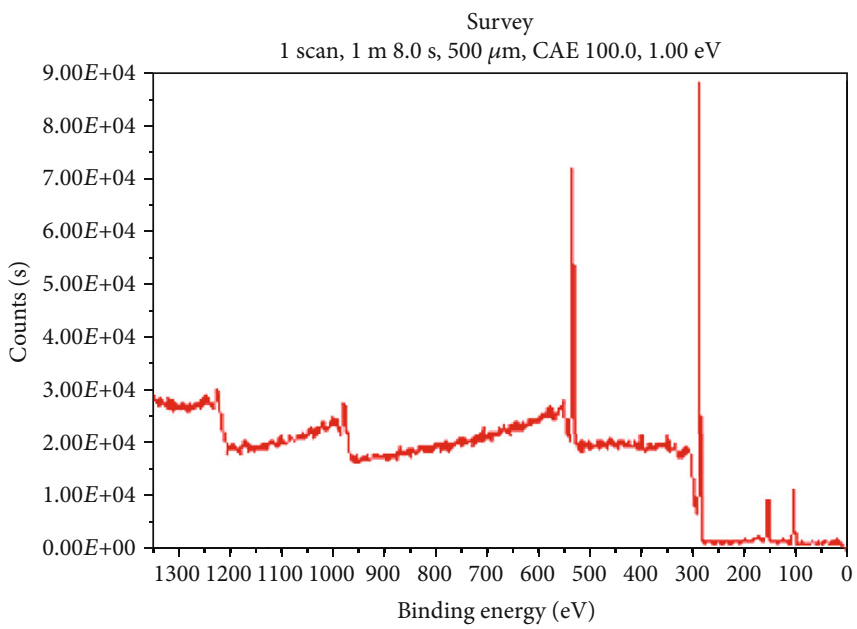

(a)

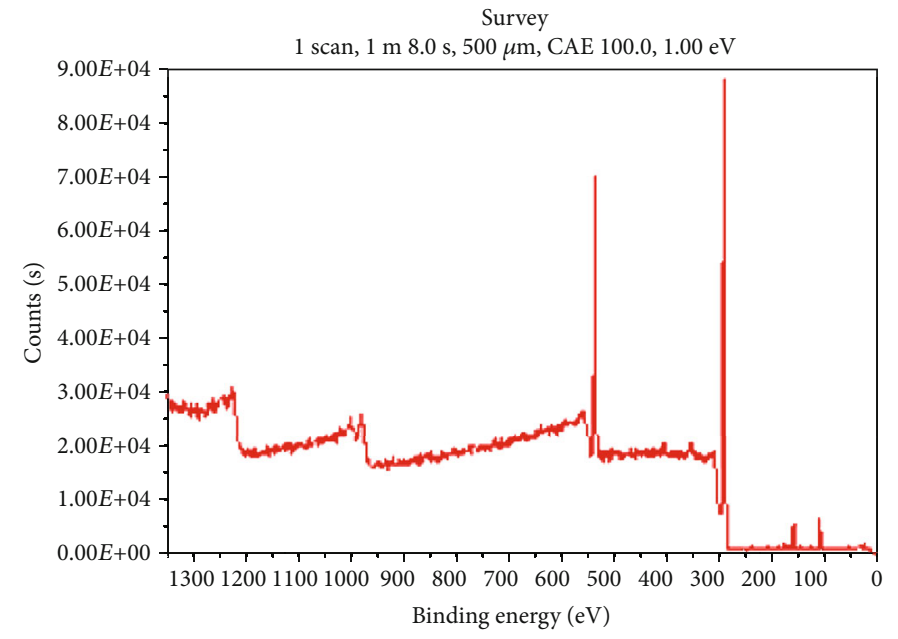

(b)

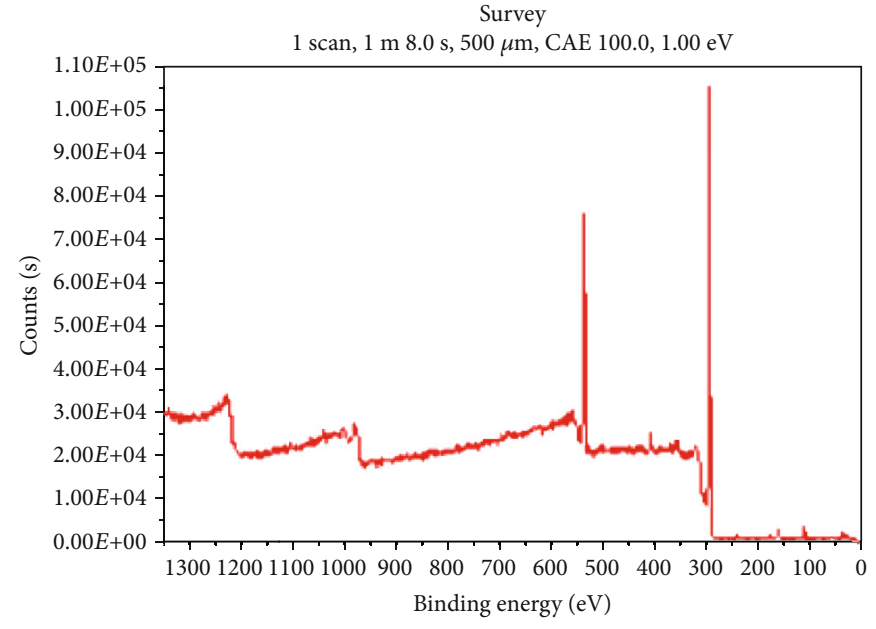

(c)

FIgure 4: The XPS full-spectrum scanning results: (a) CCF800A; (b) CCF800B; (c) CCF800C.

Figure 6 further proved that the sizing agents were speculated to use bisphenol A epoxy resin as main component.

\subsection{Thermal Aging Properties of CCF800/5228 Composites.} During long-term thermal aging, plasticization degree of thermosetting resin matrix composites reduces, while rigidity and brittleness increase. In a particular aging term, thermal treatment at a temperature below matrix glass transition temperature causes shrinkage of free volume, which leads to increase of density, rigidity, and tensile strength and decrease of toughness. In addition, expansion mismatch problem between matrix and CF often causes damage to interface, leading to mechanical property reduction. As thermal treatment at an appropriate temperature can also bring about postcuring reaction for thermosetting resin matrix composites, the relationship between thermal aging time and mechanical properties in service life of composites is complicated.

The thermal aging properties of CCF800/5228 composites are listed in Tables 6 and 7. First, the flexural strength and interlaminar shear strength at $150^{\circ} \mathrm{C}$ testing temperature significantly reduced (about $20 \%$ and $30 \%$ ), comparing those at $25^{\circ} \mathrm{C}$. The mechanical properties of 5228 matrix decreased at $150^{\circ} \mathrm{C}$, and unevenness thermal expansion of CCF800 and 5228 matrix were considered as main reasons. Second, thermal aging time up to $1000 \mathrm{~h}$ had little effect on the flexural modulus of CCF800/5228 composites at $150^{\circ} \mathrm{C}$. With the increasing aging time, the modulus fluctuated within a small range (114 to $118 \mathrm{GPa}$ ), as well as the standard deviation (2 to $5 \mathrm{GPa}$ ). It could be explained that $150^{\circ} \mathrm{C} / 1000 \mathrm{~h}$ treatment brought no changes to $\mathrm{CF}$, and the flexural modulus was mainly determined by CF. Third, with the extension of aging time, the flexural strength showed a trend of rising from $1516 \pm 62$ to $1612 \pm 56 \mathrm{MPa}$, indicating that postcuring reaction occurred. Fourth, as the aging time prolonged, the interlaminar shear performance at $25^{\circ} \mathrm{C}$ slightly reduced and that at $150^{\circ} \mathrm{C}$ showed a trend of first increasing and then decreasing. After $500 \mathrm{~h}$, the interlaminar shear strength increased from $75 \pm 1$ to $80 \pm 2 \mathrm{MPa}$. The postcuring reaction and internal stress release could be the reasons for that trend. 

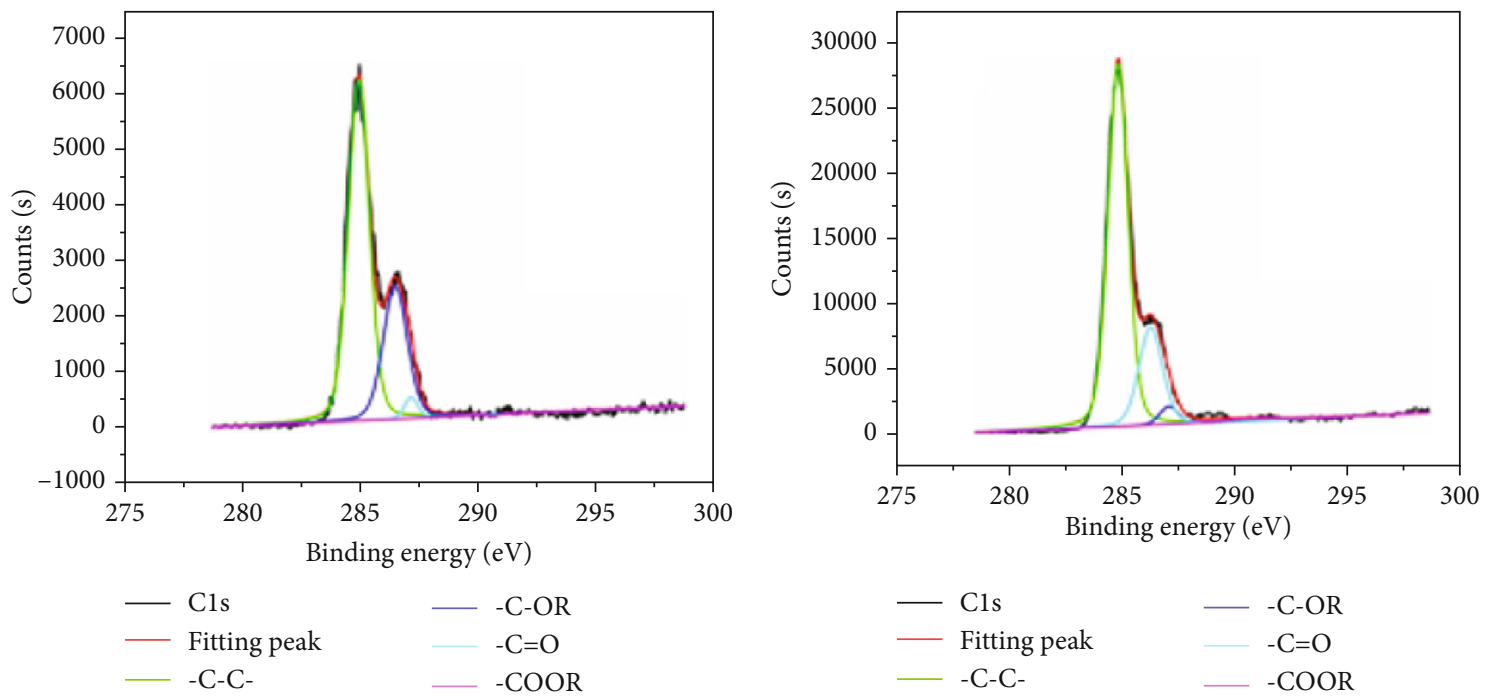

(a)

(b)

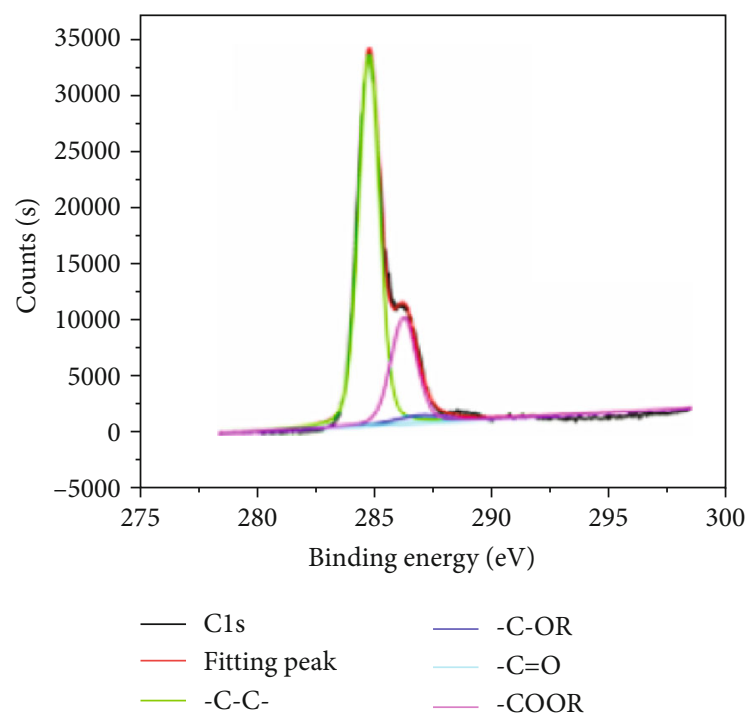

(c)

FIGURE 5: The XPS narrow scanning results of C1s fitting peak: (a) CCF800A; (b) CCF800B; (c) CCF800C.

TABLE 4: The fitting results of C1s peak.

\begin{tabular}{lccccc}
\hline Carbon fiber & $\begin{array}{c}\text {-C-C- or }-\mathrm{C}-\mathrm{H} \\
284.8 \mathrm{eV}\end{array}$ & $\begin{array}{c}\text {-C-OH or }-\mathrm{C}-\mathrm{OR} \\
286.3 \mathrm{eV}\end{array}$ & $\begin{array}{c}-\mathrm{C}=\mathrm{O} \\
287.0 \mathrm{eV}\end{array}$ & $\begin{array}{c}-\mathrm{COOH} \text { or }-\mathrm{COOR} \\
290.0 \mathrm{eV}\end{array}$ & Activated carbon atom ratio/\% \\
\hline CCF800A & 67.34 & 30.00 & 2.62 & 0.11 & 32.66 \\
CCF800B & 72.66 & 22.93 & 3.22 & 1.19 & 27.34 \\
CCF800C & 71.46 & 25.25 & 3.02 & 0.38 & 28.54 \\
\hline
\end{tabular}




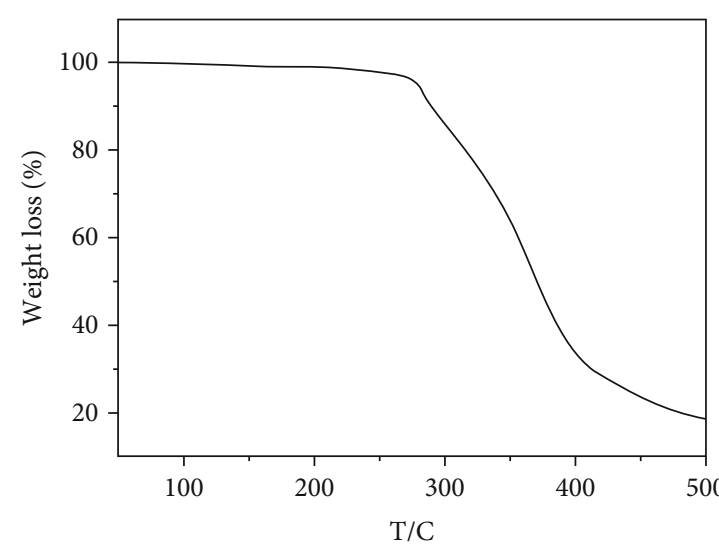

(a1)

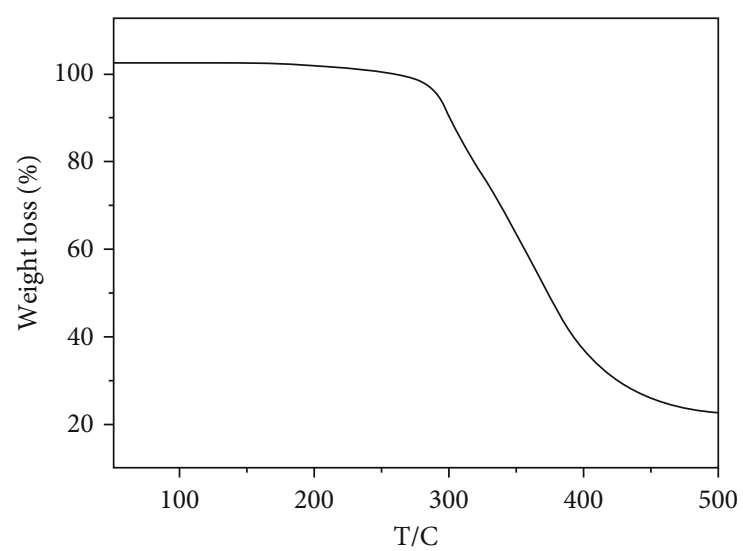

(b1)

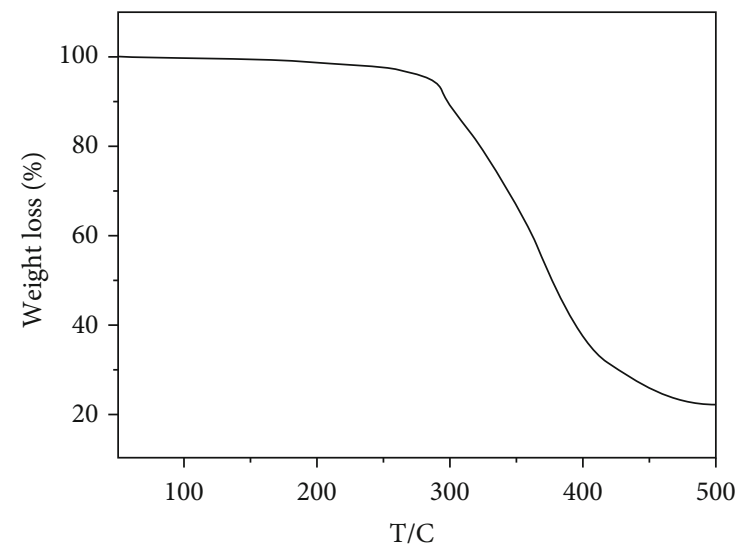

(c1)

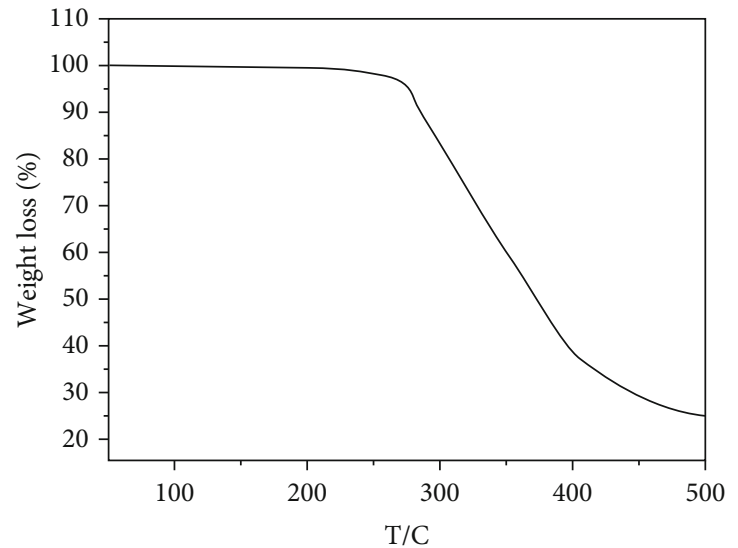

(a2)

(a)

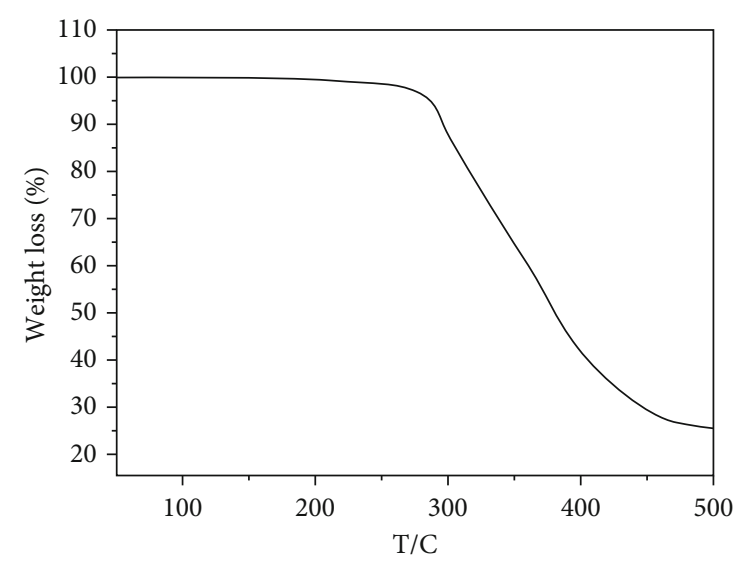

(b2)

(b)

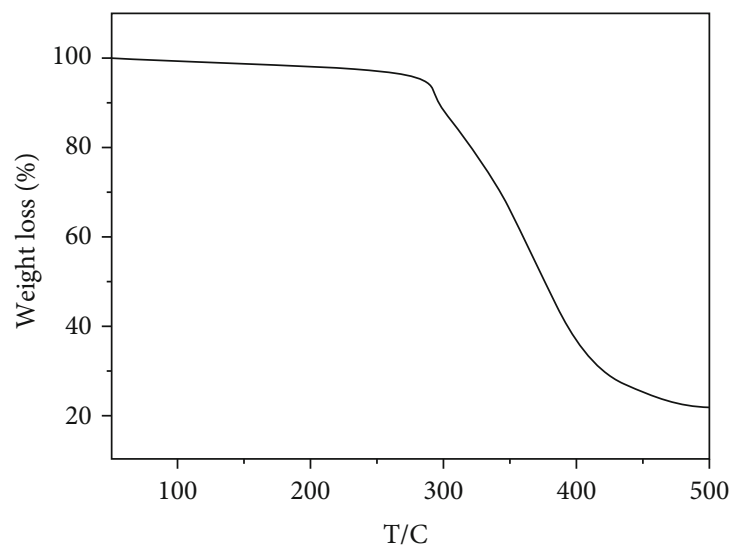

(c2)

(c)

Figure 6: TG curves in $\mathrm{N}_{2}$ and air atmosphere (1, $\mathrm{N}_{2} ; 2$, air): (a) CCF800A; (b) CCF800B; (c) CCF800C. 
TABLE 5: The weight loss of sizing agents.

\begin{tabular}{lcccc}
\hline \multirow{2}{*}{ Carbon fiber } & \multicolumn{2}{c}{ Temperature of 5\% weight loss $\left({ }^{\circ} \mathrm{C}\right)$} & \multicolumn{2}{c}{ Temperature of $10 \%$ weight loss $\left({ }^{\circ} \mathrm{C}\right)$} \\
& $\mathrm{N}_{2}$ & Air & $\mathrm{N}_{2}$ & 289.4 \\
\hline CCF800A & 279.3 & 275.9 & 289.8 & 285.6 \\
CCF800B & 283.8 & 286.2 & 295.8 & 294.9 \\
CCF800C & 285.9 & 282.8 & 297.7 & 297.2 \\
\hline
\end{tabular}

TABLE 6: The thermal aging properties of CCF800/5228 composites-flexural strength and modulus.

\begin{tabular}{|c|c|c|c|c|c|c|c|c|c|c|}
\hline \multirow{3}{*}{$\begin{array}{l}\text { Test temperature } \\
\text { Aging } \\
\text { time }(\mathrm{h})\end{array}$} & \multicolumn{5}{|c|}{ Flexural strength $(\mathrm{MPa})$} & \multicolumn{5}{|c|}{ Flexural modulus $(\mathrm{GPa})$} \\
\hline & \multicolumn{2}{|c|}{$\begin{array}{c}\text { Room temperature } \\
\left(25^{\circ} \mathrm{C}\right)\end{array}$} & \multicolumn{2}{|c|}{$150^{\circ} \mathrm{C}$} & \multirow{2}{*}{$\begin{array}{c}\text { Retention } \\
\text { rate }(\%)\end{array}$} & \multicolumn{2}{|c|}{$\begin{array}{c}\text { Room temperature } \\
\left(25^{\circ} \mathrm{C}\right)\end{array}$} & \multicolumn{2}{|c|}{$150^{\circ} \mathrm{C}$} & \multirow{2}{*}{$\begin{array}{c}\text { Retention } \\
\text { rate }(\%)\end{array}$} \\
\hline & $\begin{array}{c}\text { Average } \\
\text { value }\end{array}$ & $\begin{array}{l}\text { Standard } \\
\text { deviation }\end{array}$ & $\begin{array}{c}\text { Average } \\
\text { value }\end{array}$ & $\begin{array}{l}\text { Standard } \\
\text { deviation }\end{array}$ & & $\begin{array}{c}\text { Average } \\
\text { value }\end{array}$ & $\begin{array}{l}\text { Standard } \\
\text { deviation }\end{array}$ & $\begin{array}{c}\text { Average } \\
\text { value }\end{array}$ & $\begin{array}{l}\text { Standard } \\
\text { deviation }\end{array}$ & \\
\hline 0 & 1516 & 61 & 1220 & 44 & 80 & 117 & 5 & 118 & 4 & 101 \\
\hline 100 & 1566 & 78 & 1187 & 24 & 76 & 116 & 4 & 114 & 4 & 98 \\
\hline 250 & 1589 & 40 & 1215 & 27 & 76 & 115 & 4 & 116 & 2 & 101 \\
\hline 500 & 1609 & 57 & 1259 & 72 & 78 & 116 & 4 & 115 & 4 & 99 \\
\hline 750 & 1603 & 75 & 1288 & 36 & 80 & 117 & 3 & 116 & 4 & 99 \\
\hline 1000 & 1612 & 56 & 1235 & 60 & 77 & 117 & 4 & 116 & 4 & 99 \\
\hline
\end{tabular}

TABLE 7: The thermal aging properties of CCF800/5228 composites-interlaminar shear strength.

\begin{tabular}{|c|c|c|c|c|c|}
\hline \multirow{3}{*}{$\begin{array}{l}\text { Test temperature } \\
\text { Aging time }(\mathrm{h})\end{array}$} & \multicolumn{5}{|c|}{ Interlaminar shear strength $(\mathrm{MPa})$} \\
\hline & \multicolumn{2}{|c|}{ Room temperature $\left(25^{\circ} \mathrm{C}\right)$} & \multicolumn{2}{|c|}{$150^{\circ} \mathrm{C}$} & \multirow{2}{*}{ Retention rate $(\%$} \\
\hline & Average value & Standard deviation & Average value & Standard deviation & \\
\hline 0 & 107 & 2 & 75 & 1 & 70 \\
\hline 100 & 107 & 5 & 78 & 2 & 73 \\
\hline 250 & 106 & 4 & 79 & 3 & 75 \\
\hline 500 & 103 & 3 & 80 & 2 & 78 \\
\hline 750 & 105 & 3 & 75 & 2 & 71 \\
\hline 1000 & 105 & 2 & 77 & 2 & 73 \\
\hline
\end{tabular}

Fifth, synthesizing the interlaminar shear strength results from $0 \mathrm{~h}$ to $1000 \mathrm{~h}$; the retention rate of $150^{\circ} \mathrm{C}$ was higher than $70 \%$.

\section{Conclusions}

CCF800 CF coated with three sizing agents varying in molecular weight were studied. The change of molecular weight did not influence the length, number, and distribution of surface grooves much. CCF800 CF with small molecular weight of sizing agent exhibited low surface roughness and high activated carbon atom proportion. After thermal aging at $150^{\circ} \mathrm{C}$, the flexural strength and interlaminar shear strength of CCF800/5228 composites reduced significantly, comparing those at $25^{\circ} \mathrm{C}$, while thermal aging had little effect on the flexural modulus. For CCF800/5228 composites, the retention rate of interlaminar shear strength at $150^{\circ} \mathrm{C}$ was higher than $70 \%$ from 0 to $1000 \mathrm{~h}$. The interlaminar shear performance at $150^{\circ} \mathrm{C}$ showed a trend of increasing at the beginning and then decreasing.

\section{Data Availability}

Some or all data that support the findings of this study are available from the corresponding author upon reasonable request.

\section{Conflicts of Interest}

The authors declare that they have no conflicts of interest.

\section{References}

[1] S. Chand, "Review carbon fibers for composites," Journal of Materials Science, vol. 35, no. 6, pp. 1303-1313, 2000.

[2] J. Kim and Y. Mai, "High strength, high fracture toughness fibre composites with interface control -A review," Composites Science and Technology, vol. 41, no. 4, pp. 333-378, 1991.

[3] P. Peters and H. Albertsen, "The influence of fibre surface treatment on the formation of an interphase in CFRP," Journal of Materials Science, vol. 28, no. 4, pp. 1059-1066, 1993. 
[4] M. Akonda, C. Lawrence, and B. Weager, "Recycled carbon fibre-reinforced polypropylene thermoplastic composites," Composites. Part A, Applied Science and Manufacturing, vol. 43, no. 1, pp. 79-86, 2012.

[5] B. Vieille, V. M. Casado, and C. Bouvet, "About the impact behavior of woven-ply carbon fiber-reinforced thermoplasticand thermosetting-composites: a comparative study," Composite Structures, vol. 101, pp. 9-21, 2013.

[6] J. Markarian, "Processing and recycling advantages drive growth in thermoplastic elastomers," Plastics, Additives and Compounding, vol. 6, pp. 22-25, 2004.

[7] J. Karger-Kocsis, H. Mahmood, and A. Pegoretti, "Recent advances in fiber/matrix interphase engineering for polymer composites," Progress in Materials Science, vol. 73, pp. 1-43, 2015.

[8] M. Sharma, S. Gao, E. Mäder, H. Sharma, L. Y. Wei, and J. Bijwe, "Carbon fiber surfaces and composite interphases," Composites Science and Technology, vol. 102, pp. 35-50, 2014.

[9] S. Tiwari and J. Bijwe, "Surface treatment of carbon fibers - a review," Procedia Technology, vol. 14, pp. 505-512, 2014.

[10] M. Mudhukrishnan, P. Hariharan, K. Palanikumar, and B. Latha, "Tool materials influence on surface roughness and oversize in machining glass fiber reinforced polypropylene (GFR-PP) composites," Materials and Manufacturing Processes, vol. 32, no. 9, pp. 988-997, 2017.

[11] M. Haddad, R. Zitoune, F. Eyma, and B. Castanie, "Influence of machining process and machining induced surface roughness on mechanical properties of continuous fiber composites," Experimental Mechanics, vol. 55, no. 3, pp. 519-528, 2015.

[12] X. Wang, Z. Huang, M. Lai, L. Jiang, Y. Zhang, and H. Zhou, "Highly enhancing the interfacial strength of CF/PEEK composites by introducing PAIK onto diazonium functionalized carbon fibers," Applied Surface Science, vol. 510, p. 145400, 2020.

[13] X. Yuan, Z. Bo, C. Xun, J. Liu, K. Qiao, and J. Yu, “Optimization of interfacial properties of carbon fiber/epoxy composites via a modified polyacrylate emulsion sizing," Applied Surface Science, vol. 401, pp. 414-423, 2017.

[14] W. Jiao, Y. Cai, W. Liu et al., "Preparation of carbon fiber unsaturated sizing agent for enhancing interfacial strength of carbon fiber/vinyl ester resin composite," Applied Surface Science, vol. 439, pp. 88-95, 2018.

[15] J. Moosburger-Will, M. Bauer, E. Laukmanis et al., "Interaction between carbon fibers and polymer sizing: influence of fiber surface chemistry and sizing reactivity," Applied Surface Science, vol. 439, pp. 305-312, 2018.

[16] S. L. Chuang, N. J. Chu, and W. T. Whang, "Effect of polyamic acids on interfacial shear strength in carbon fiber/aromatic thermoplastics," Journal of Applied Polymer Science, vol. 41, no. 12, pp. 373-382, 1990.

[17] R. L. Zhang, Y. D. Huang, L. Liu, Y. R. Tang, D. Su, and L. W. $\mathrm{Xu}$, "Effect of emulsifier content of sizing agent on the surface of carbon fibres and interface of its composites," Applied Surface Science, vol. 257, no. 8, pp. 3519-3523, 2011.

[18] Q. Wu, R. Zhao, T. Xi, X. Yang, and J. Zhu, "Comparative study on effects of epoxy sizing involving $\mathrm{ZrO}_{2}$ and GO on interfacial shear strength of carbon fiber/epoxy composites through one and two steps dipping routes," Composites. Part A, Applied Science and Manufacturing, vol. 134, p. 105909, 2020.
[19] N. L. Gu, C. X. Chu, J. N. Guo, H. Y. Ge, and C. S. Jin, "Effect of carbon nanotubes sizing agent on the mechanical properties of carbon fiber/PP composite," Materials Science Forum, vol. 993, pp. 684-688, 2020.

[20] N. Li, L. Zong, Z. Wu et al., "Compatibilization effect of aminated poly (phthalazinone ether ketone) $s$ in carbon fiberreinforced copoly (phthalazinone ether sulfone) s composites," Polymer Composites, vol. 39, no. 11, pp. 4139-4147, 2018.

[21] Y. F. Niu, Y. Yang, and X. R. Wang, "Investigation of the interphase structures and properties of carbon fiber reinforced polymer composites exposed to hydrothermal treatments using peak force quantitative nanomechanics technique," Polymer Composites, vol. 39, no. S2, pp. E791-E796, 2018. 